\title{
Formação contínua centrada na escola e desenvol- vimento profissional docente: um estudo de caso
}

Pedro Ribeiro Mucharreira

Universidade de Lisboa

\section{Resumo}

presente artigo apresenta resultados parciais de uma investigação em torno do papel da formação contínua, centrada na escola, no desenvolvimento profissional docente. A investigação decorreu numa escola privada nos arredores de Lisboa, em Portugal. O objetivo central foi o de analisar o papel da formação contínua de professores, centrada no contexto específico da escola que se constituiu como campo de estudo, no estabelecimento de uma comunidade de aprendizagem e promotora de desenvolvimento profissional docente. Em termos metodológicos recorreu-se a entrevistas semiestruturadas a 20 indivíduos que se consideraram informantes-chave, como professores, chefias de topo e intermédias, bem como formadores internos e externos. As principais conclusões da investigação apontam no sentido de um efetivo estabelecimento de uma comunidade de aprendizagem, que reflete na e sobre a prática, mas onde é relevado o tempo como principal constrangimento no âmbito da planificação e consequente implementação das ações de formação.

Palavras-chave: Formação de professores. Formação centrada na escola. Desenvolvimento profissional docente.

\section{School-based teacher training and teacher professional development: a case study}

\section{Abstract}

This research presents the partial data from a doctoral thesis, still in development, focusing the conducted research in the role of school-based teacher training in the teacher professional development. The investigation occurred in a private school on the outskirts of Lisbon, in Portugal. The main objective was to analyze the role of continuous training of teachers, focused on the specific context of the school that constituted itself as a field of study, in the establishment of a community of learning and promoter of teacher professional development. In methodological terms it was resorted to semi-structured interviews to 20 individuals who were considered key informants, such as, teachers, top and middle leadership, as well as internal and external trainers. The main conclusions of the study point towards an effective establishment of a community learning that reflects in and over the practice, but where is highlighted the time as a primary constraint in the scope of planning and the subsequent implementation of training actions.

Keywords: Teacher training. School-based teacher training. Teacher professional development 


\section{La formación basada en la escuela y el desarrollo profesional de los docentes: un estudio de caso}

\section{Resumen}

Este estudio presenta datos parciales de una tesis doctoral, todavía en desarrollo, enfocando la investigación llevada a cabo en el papel de la formación del profesorado basada en la escuela en el desarrollo profesional de los maestros. La investigación hay recorrido en una escuela privada en las afueras de Lisboa, en Portugal. El objetivo principal fue analizar el papel de la formación continua de los profesores, centrado en el contexto específico de la escuela, en el establecimiento de una comunidad de aprendizaje y promotor del desarrollo profesional de los maestros. En términos metodológicos, se recurrió a entrevistas semiestructuradas a 20 individuos que eran considerados informantes clave, tales como, maestros, principales líderes, así como formadores internos y externos. Las principales conclusiones del estudio apuntan hacia un establecimiento eficaz de una comunidad de aprendizaje que refleja en y sobre la práctica, pero en donde se destaca el tiempo como una limitación primaria en el ámbito de la planificación y la posterior ejecución de las acciones de formación.

Palabras clave: La formación del profesorado. Formación de Profesores Basado en la Escuela. Desarrollo profesional para maestros.

\section{Introdução}

A formação de professores continua a ser uma temática que suscita grande interesse em Portugal e no mundo, não apenas num âmbito escolar e académico, mas num plano mais alargado, ao nível político, económico e social, sendo encarada como um fator crítico de sucesso tendo em vista a procura do sucesso educativo (HILTON; FLORES; NIKLASSON, 2013).

$O$ presente artigo baseia-se numa investigação, ainda em desenvolvimento, sobre o papel da formação contínua de professores, centrada na escola, no desenvolvimento profissional docente e no próprio projeto educativo em geral.

Recorrendo-se a um estudo de caso, através de entrevistas semi-estruturadas a diferentes atores educativos, a investigação pretendeu obter resultados que evidenciassem as relações que possam estabelecer-se entre a política de formação contínua, centrada na escola, e as outras dimensões em estudo - o 
projeto educativo e o desenvolvimento profissional dos professores. Para além destas, foram também alvo da nossa atenção outros elementos que permitissem compreender em que medida a organização escolar estudada se poderia enquadrar numa lógica do que habitualmente se designa por organizações escolares aprendentes.

Neste texto apresentamos apenas os resultados da dimensão "conceções e práticas sobre a concretização das políticas de formação contínua no contexto concreto da escola", desdobrada através da análise de duas das categorias constituintes dessa dimensão, ou seja, uma respeitante à "aplicação das políticas de formação contínua" e outra, relativa à "formação contínua e desenvolvimento profissional docente".

\section{Formação contínua de professores}

A formação de professores, na sua generalidade, continua a ser encarada como um fator crítico de sucesso tendo em vista a procura do sucesso educativo. Neste momento é consensual a ideia que uma formação docente de qualidade, tanto a inicial como a contínua, contribui para a melhoria do 40 ensino, podendo tal medir-se pela melhoria das aprendizagens dos discentes. Parece ser, contudo, menos consensual a avaliação da qualidade, pois esta estará condicionada pelos diferentes contextos em que se operacionaliza e concretiza cada uma das ações de formação docente (HILTON; FLORES; NIKLASSON, 2013 ; FLORES, 20151.

Apesar de nos últimos anos, estar disponível um significativo número de investigações na área da formação contínua de professores, particularmente em Portugal, a quase totalidade dos trabalhos centra-se mais na formação da iniciativa dos centros de formação, vulgarmente conhecidos por Centros de Formação das Associações de Escolas (CFAE), do que propriamente na formação contínua da iniciativa das escolas, e dos seus efeitos em contextos escolares específicos.

A investigação em Portugal não tem assim acompanhado uma tendência, notória, a nível internacional, de procurar compreender melhor o papel dessa formação contínua centrada na escola no desenvolvimento profissional docente. Oportunidades essas que, segundo Forte e Flores (2014), trarão benefícios para a prática docente e porventura para a própria organização escolar, podendo de igual forma promover as melhores decisões ao nível 
das políiticas formativas. No Quadro 1, é possível constatar a evolução em Portugal das modalidades de formação em que se estruturaram as ações formativas disponibilizadas pelas diferentes entidades acreditadas pelo Conselho Científico-Pedagógico da Formação Contínua (CCPFC).

\section{Quadro 1}

\section{Evolução da Distribuição Percentual de Ações por Modalidade de Formação}

\begin{tabular}{|c|c|c|c|c|c|c|c|c|}
\hline Modalidades & $\mathbf{1 9 9 7}$ & $\mathbf{2 0 0 8}$ & $\mathbf{2 0 0 9}$ & $\mathbf{2 0 1 0}$ & $\mathbf{2 0 1 1}$ & $\mathbf{2 0 1 2}$ & $\mathbf{2 0 1 3}$ & $\mathbf{2 0 1 4}$ \\
\hline Curso de Formação & $82,7 \%$ & $31,1 \%$ & $64,58 \%$ & $56,60 \%$ & $59,37 \%$ & $61,07 \%$ & $72,7 \%$ & $63,98 \%$ \\
\hline Módulo de Formação & $4,6 \%$ & $16,9 \%$ & $2,07 \%$ & $2,3 \%$ & $3,2 \%$ & $1,96 \%$ & $0,88 \%$ & $2,07 \%$ \\
\hline Disciplinas Singulares & - & - & $1,47 \%$ & $8,17 \%$ & $0,42 \%$ & $4,84 \%$ & $1,17 \%$ & $1 \%$ \\
\hline Seminário & $1,8 \%$ & $0,4 \%$ & $0,19 \%$ & $0,18 \%$ & $0,93 \%$ & $0,09 \%$ & $0,05 \%$ & $0,07 \%$ \\
\hline Oficina de Formação & $5,3 \%$ & $45,3 \%$ & $29,48 \%$ & $27,68 \%$ & $30,73 \%$ & $28,35 \%$ & $22,49 \%$ & $30,73 \%$ \\
\hline Estágio & $0 \%$ & $0,2 \%$ & $0,1 \%$ & $0,16 \%$ & $0,05 \%$ & $0,07 \%$ & $0,08 \%$ & $0 \%$ \\
\hline Projeto & $0,6 \%$ & $1 \%$ & $0,58 \%$ & $3,05 \%$ & $3,61 \%$ & $1,94 \%$ & $1,14 \%$ & $0,83 \%$ \\
\hline Círculo de Estudos & $5 \%$ & $5,1 \%$ & $1,53 \%$ & $1,86 \%$ & $1,69 \%$ & $1,68 \%$ & $1,49 \%$ & $1,32 \%$ \\
\hline Total & $100 \%$ & $100 \%$ & $100 \%$ & $100 \%$ & $100 \%$ & $100 \%$ & $100 \%$ & $100 \%$ \\
\hline $\begin{array}{c}\text { Formação centrada } \\
\text { nos conteúdos }\end{array}$ & $89,1 \%$ & $48,6 \%$ & $68,31 \%$ & $67,41 \%$ & $63,92 \%$ & $67,96 \%$ & $74,8 \%$ & $67,13 \%$ \\
\hline $\begin{array}{c}\text { Formação centra- } \\
\text { da nos contextos } \\
\text { escolares }\end{array}$ & $10,9 \%$ & $51,4 \%$ & $31,69 \%$ & $32,59 \%$ & $36,08 \%$ & $32,04 \%$ & $25,2 \%$ & $32,87 \%$ \\
\hline
\end{tabular}

Fonte | Adaptado de CCPFC (2015).

Da interpretação dos dados apresentados é possível verificar que de 2010 a 2013 a modalidade "cursos de formação" foi reforçando o seu peso relativo em relação às outras modalidades, verificando-se um decréscimo em 2014 que não colocou em questão a liderança enquanto modalidade mais utilizada nos últimos anos, contrariamente à realidade de 2008. A segunda modalidade mais utilizada tem sido a "oficina de formação", notando-se, contudo, um registo eminentemente cíclico ao longo dos últimos anos. As restantes modalidades de formação têm tido um papel residual ao nível das políticas formativas. Da análise do Quadro 1 é ainda possível notar que, nos últimos anos, excetuando mais uma vez o ano de 2008, as ações de formação são fortemente centradas nos conteúdos, ações de menor duração, em detrimento 
de uma formação mais centrada nos respetivos contextos escolares, muitas vezes estando-lhe adstrita uma maior carga horária.

A aposta na formação contínua dos professores, mais ou menos contextualizada, pode contribuir para uma aprendizagem continuada de conhecimentos e competências que a formação inicial não consegue proporcionar, para mais nestes tempos de crescente globalização, em que a educação vivencia grandes incertezas que exigem uma grande abertura à mudança, relevando Nóvoa (2009) o papel nuclear e insubstituível dos docentes nestes crescentes desafios que o início do século XXI tem proporcionado. Neste âmbito, defende a aposta na formação contínua docente como fator decisivo de desenvolvimento profissional docente, particularmente quando esta se centra nos contextos específicos de cada escola e nas legítimas expetativas pessoais de cada professor, não deixando de relevar o trabalho em equipa, o exercício coletivo da profissão e a importância dos projetos educativos de escola (NÓVOA, 2009).

De acordo com o exposto por Eraut (1977), podemos referir-nos aos seguintes paradigmas da formação contínua de professores, de acordo com as finalidades a que se propõem: o paradigma do deficit, em que a principal fina42 lidade da ação de formação consiste na pretensão de suprir falhas ocorridas com formações anteriores; o paradigma do crescimento, que passa pela identificação dos interesses do professor, com o propósito de poder conduzir ao seu desenvolvimento pessoal e profissional; o paradigma da mudança, que tenta promover mudanças efetivas conducentes a um envolvimento dos professores, particularmente junto dos professores habitualmente mais recalcitrantes a mudar o que é importante ser retificado; e o paradigma da resolução de problemas, que consiste na pretensão de que a ação de formação possa ajudar na resolução de problemas reais identificados na escola, sendo assim o programa ajustado às necessidades reais sentidas.

Os paradigmas de formação contínua permitem assim enquadrar e justificar de forma ampla as políticas formativas, colocando em relação as necessidades do sistema educativo no seu todo, das escolas e dos professores em particular, tendo em conta as especificidades próprias de cada docente e grupo de docentes.

A formação contínua poderá desta forma constituir-se como um agente de mudança e transformação da escola na demanda de uma maior qualidade 
do ensino ministrado, com implicações positivas nas aprendizagens dos alunos (FULLAN, 1991), como se fosse, tendo presente as ideias de Rocha (2014), um processo alquímico, potenciando um desenvolvimento pessoal e profissional dos docentes envolvidos. Para tal se efetivar é também crucial que as ações de formação contínua se estruturem no projeto educativo da organização escolar e possam ser encaradas como oportunidades de aprendizagem e mudança e não apenas tendo-thes adstrita a perspetiva redutora de apenas poderem servir para a obtenção de creditação que permita, eventualmente, uma progressão na carreira (JESUS, 2000; ROCHA, 2014).

$\bigcirc$ recurso a políticas formativas que pretendam mudanças significativas, particularmente quando contextualizadas a uma determinada realidade escolar (MUCHARREIRA, 2014), necessita de uma eficaz e eficiente identificação dos problemas de formação dos intervenientes (LESNE, 1984). Alinhados nesta necessidade de identificação das necessidades formativas, LoucksHorsley, Hewson, Love e Stiles (1998), para além de Gordon, Jacobs e Solis (20 14) apontam que só nessa premissa as ações poderão ser úteis e produzir os objetivos a que se propõem, pois, segundo os seus estudos, os professores só estarão plenamente envolvidos na ação de formação se esta levar em linha de conta as necessidades percecionadas por estes, apontando também que, de forma genérica, esta pretensão raramente é posta em prática. Este aspeto é considerado central para justificar a ineficácia das políticas formativas em muitos contextos educativos nas últimas décadas, onde se enquadra a realidade portuguesa (CANÁRIO, 1994).

\section{1. Formação contínua centrada na escola}

Reforçando o foco na formação contínua centrada na escola, importa referir que este conceito foi emergindo na década de 90 (HEILBRONN, 1995) e, à luz das considerações de Barroso (1997), por formação centrada na escola assumem-se todas as iniciativas formativas que dão corpo à política de formação de uma escola, respondendo às suas necessidades específicas. Neste sentido, estando o foco ou até mesmo o local onde decorre a formação, centrada na escola, verifica-se uma mudança de paradigma, pois são os agentes educativos dessa escola que definem as estratégias formativas em função da sua realidade, libertando-se da definição de estratégias estritamente centralizadas pelos organismos centrais (IMBERNÓN, 2006). 
A formação centrada na escola institucionaliza no seu contexto um processo de aprendizagem contínua, perspetivando iniciativas reflexivas e formativas que possibilitam aos professores o questionamento das suas práticas, podendo contribuir para a qualidade do ensino e assim, em última instância, para as aprendizagens efetivas e duradouras dos alunos. Para além deste desenvolvimento profissional docente, que pode surgir em consequência desta aposta numa formação contextualizada, existe também a possibilidade de ocorrer uma aprendizagem coletiva de toda a estrutura organizacional (BOLIVAR, 1997; BARROSO, 1997).

Para Schön (2000) e Dubar (2003) as políticas de formação de uma organização escolar, quando associadas e pensadas tendo em conta o projeto educativo e o seu contexto específico, são uma via para ultrapassar uma conceção instrumental e estandardizada da formação (CANÁRIO, 1992), fomentando a atividade comunicacional e reflexiva dos docentes. Com isto, possibilita-se encarar as ações de formação numa outra lógica, ganhando os docentes um papel reforçado, proativo, deixando de ser encarados como meros recetores para poderem passar a produtores de novos saberes através dessa experiência em contexto (SILVA, 2003).

44 Ten Dam e Blom (2006) consideram a aposta na formação centrada na escola como uma das mudanças mais significativas e notáveis na história recente da formação de professores, assinalando, em consequência disto, a diminuição da primazia das Instituições de Ensino Superior (IES) na implementação da formação contínua docente, passando as escolas a assumir cada vez mais as suas políticas de formação contínua, nas suas diferentes fases de implementação.

Como vantagens, os autores apontam a possibilidade de tornar a formação mais atrativa e promover a forte qualificação dos professores ajustada às necessidades específicas (McLAUGHLIN, 2003) e reforço do trabalho cooperativo tendente a um desenvolvimento profissional docente (KWAKMAN, 20031.

Já quanto a aspetos a ter em atenção, é de realçar o facto da formação centrada na escola poder envolver em demasia os docentes, não thes sobrando tempo, espaço e condições favoráveis para uma necessária reflexão e interiorização de todos os conhecimentos e processos retirados das ações de formação (FURLONG, 2002). Adicionalmente, outros constrangimentos 
que podem dificultar a implementação desta formação centrada na escola, para além da falta de tempo e impreparação técnica e científica dos docentes para estas iniciativas (HEILBRONN, 1995), existe a possibilidade de surgirem interesses corporativos da classe docente ou uma formação que esteja exageradamente limitada à ação docente, olvidando os alunos e a restante comunidade escolar (DAY, 2001), bem como a possibilidade de com esta se poder ignorar ou subvalorizar as necessidades individuais dos docentes, em favor de uma aposta quase exclusiva das necessidades da organização, podendo levar a uma perda de envolvimento e comprometimento individual docente (BELL; DAY, 1991).

\subsection{Comunidades de prática e desenvolvimento profissional docente}

No entendimento de Clarke e Hollingsworth (2002), os professores que se envolvem de forma efetiva em processos conjuntos de reflexão, construindo efetivas comunidades de aprendizagem, conseguem depois aprender a partilhar os conhecimentos adquiridos por si próprios, tendo assim oportunidade de aperfeiçoar práticas que possam beneficiar as aprendizagens dos alunos (LITTLE, 1982; HARGREAVES, 1998; LIMA, 2002; HERDEIRO, SILVA, 2008).

Ainda segundo Herdeiro e Silva (2008) o ensino é hoje encarado como um trabalho em equipa em constante reflexão e desenvolvimento, pois as tarefas que the estão adstritas são cada vez mais complexas, onde a vivência real e concreta de práticas reflexivas implica o domínio de processos cognitivos e metacognitivos e uma grande capacidade de análise crítica das práticas. Só desta forma, segundo Herdeiro e Silva (2008) e Roldão (2007), a prática reflexiva permitirá a construção de conhecimento que possa ser explicado, fundamentado e verificável, podendo conduzir a melhorias nas práticas docentes, aprendizagens significativas nos alunos, reforço de práticas colaborativas e desenvolvimento organizacional (LITTLE, 1982; ROSENHOLTZ, 1989; HARGREAVES, FULLAN, 1992; DAY, 2001; LEVINE, MARCUS, 2010; FORTE, FLORES, 2014).

Para Ashburn (1995), como para Harris e Anthony (2001), a colegialidade é importante pois leva os professores a refletir e a trabalhar juntos nas diferentes dimensões da vida escolar, um pouco à imagem da cooperação 
e colaboração que tentam promover em contexto de sala de aula aos seus alunos. A colegialidade, ao promover espaços e tempos de encontro dos professores (ROGERS, 1973), pode assim contribuir para quebrar o isolamento dos professores e reforçar a capacidade de trabalho individual e coletiva, promovendo desta forma o desenvolvimento profissional (LITTLE, 1990). Apesar destes benefícios, muitos são os professores, de diferentes níveis de ensino, a reconhecerem a dificuldade em encontrarem espaços e tempos favoráveis para uma auto e heteroreflexão capazes de consagrar e otimizar essas práticas colaborativas (ROY, DUFAULT; CHÂTEAUVERT, 2014). Um modelo possível, entre outros, de operacionalização de uma reflexão crítica docente pode assentar no modelo patente na Figura 1.

Figura 1

\section{Modelo Prático-Reflexivo - Desenvolvimento Profissional Docente}

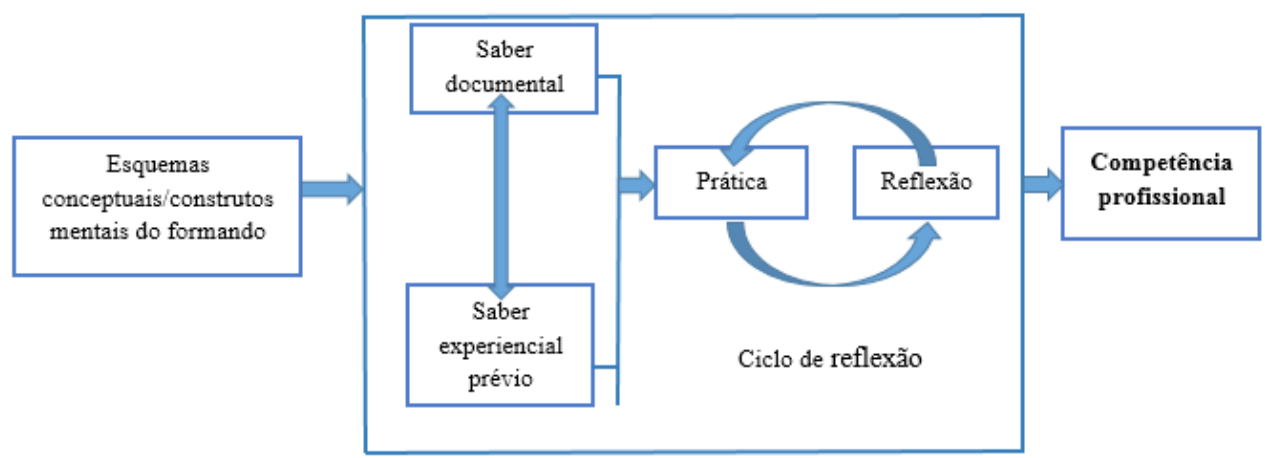

Fonte | Wallace (1991)

Neste modelo, o conhecimento documental e experiencial prévios vão permitir a concretização de um ciclo reflexivo que se dá em constante interação com a prática, permitindo assim a plena integração de competências. Neste modelo adquire especial relevância o papel do supervisor ou critical friend, no sentido de orientar e encorajar a reflexão na e sobre a ação e que esta possa conduzir a um efetivo desenvolvimento profissional docente.

No entendimento de alguns autores, as mudanças significativas na escola só se materializam quando os professores atingem um elevado comprometimento com o seu desenvolvimento profissional (CORNISH; JENKINS, 2012), potenciado por experiências de reflexão em contexto e com aplicação nas 
suas práticas, indicando também Clarke e Hollingsworth (2002) que os professores que se envolvem de forma efetiva em processos conjuntos de reflexão conseguem depois aprender a partilhar os conhecimentos adquiridos por si próprios.

Defendendo o mesmo raciocínio, Forte e Flores (2014) enaltecem que para se efetivar um desenvolvimento profissional docente contínuo, permanente, para além de um reforço dos conhecimentos, têm que se efetivar mudanças concretas que só serão possíveis se os docentes acreditarem verdadeiramente nessas mesmas ideias e propostas de mudança e as queiram colocar em prática (NÓVOA, 1992; DAY, 2001 ; VEIGA SIMÃO, CAETANO, FLORES, 2005; FORTE, FLORES, 2014).

\subsection{Contexto do estudo - a escola e o seu projeto educativo}

No que concerne ao projeto educativo da escola onde foi desenvolvida a investigação, este constrói-se a partir de 4 pilares - vertente académica, formação humana, pastoral e atividades de complemento curricular (ACC) -, assente na procura de exercício de uma pedagogia em específico e na construção interdisciplinar de um currículo do mar, conforme é possível constatar na Figura 2.

Figura 2

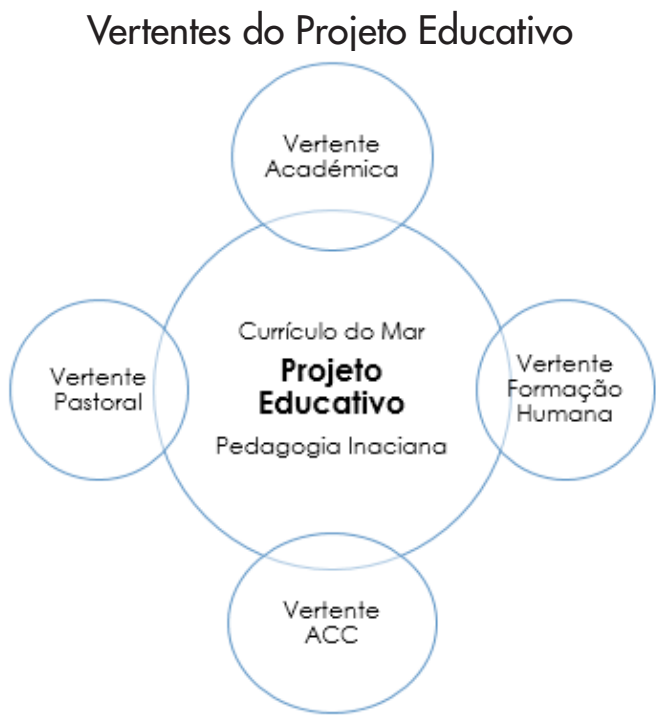

Fonte | Elaboração própria 
$O$ projeto educativo estrutura-se e ao mesmo tempo emerge da designada pedagogia inaciana, onde é proposto um modelo de ensino e de aprendizagem onde se procura e estimula o rigor académico, científico e humanista (TRINDADE; BAHIA; MUCHARREIRA, 2015).

A dinâmica de implementação da pedagogia inaciana, ou paradigma pedagógico inaciano (PPI), passa pela assunção da experiência, reflexão, ação e avaliação, numa constante interação com o contexto em que se insere (STREETMAN, 2015; HOOVER, 2015; TRINDADE; BAHIA; MUCHARREIRA, 20151.

\section{Metodologia}

Em termos metodológicos, a investigação assumiu uma natureza qualitativa, materializada num estudo de caso múltiplo, seguindo os pressupostos de Bardin (2009), Bogdan e Biklen (1994).

A investigação incidiu numa escola privada, da área metropolitana de Lisboa, em Portugal, cuja oferta educativa vai do ensino pré-escolar ao $12^{\circ}$ 48 ano (ensino médio), estando matriculados cerca de 1500 alunos no ano letivo $2013 / 2014$. No mesmo período, o corpo docente era constituído por 106 professores e educadores de infância.

Os instrumentos de recolha de dados consistiram na recolha e análise documental, entrevistas semi-estruturadas e a observação direta que permitiu a conceção de notas de campo.

Neste artigo, tal como já referido, apresentam-se apenas os dados resultantes de 2 categorias das entrevistas semiestruturadas.

As entrevistas semiestruturadas foram realizadas a 20 informantes-chave, selecionados numa primeira instância tendo em atenção a possibilidade de abarcar grande parte da estrutura organizacional e depois, para melhor compreender a realidade estudada e à luz dos objetivos do estudo, sujeitos que para além de professores acumulavam com outras funções, de chefia ou de formador, interno ou externo.

Ainda quanto às entrevistas, foram seguidos os pressupostos de Bogdan e Biklen (1994), optando-se assim nesta investigação, pelo já exposto, por 
selecionar uma amostra intencional, apresentando-se de seguida, no Quadro 2, a caracterização biográfica desta.

\section{Quadro 2}

\section{Dados Biográficos dos Informantes-Chave $(\mathrm{N}=20)$}

\begin{tabular}{|c|c|c|}
\hline & Fr. & $\%$ \\
\hline \multicolumn{3}{|l|}{ Sexo } \\
\hline Sexo masculino & 9 & 45 \\
\hline Sexo feminino & 11 & 55 \\
\hline \multicolumn{3}{|l|}{ Idade } \\
\hline Entre 20 e 30 anos & 0 & 0 \\
\hline Entre 31 e 40 anos & 9 & 45 \\
\hline Entre 41 e 50 anos & 6 & 30 \\
\hline Mais de 51 anos & 5 & 25 \\
\hline \multicolumn{3}{|l|}{ Formação académica } \\
\hline Licenciatura & 10 & 50 \\
\hline Mestrado & 9 & 45 \\
\hline Doutoramento & 1 & 5 \\
\hline \multicolumn{3}{|l|}{ Experiência profissional } \\
\hline Até 4 anos & 0 & 0 \\
\hline Entre 5 e 7 anos & 2 & 10 \\
\hline Entre 8 e 14 anos & 6 & 30 \\
\hline Entre 15 e 22 anos & 5 & 25 \\
\hline Entre 23 e 40 anos & 7 & 35 \\
\hline \multicolumn{3}{|l|}{ Antiguidade na escola } \\
\hline Até 2 anos & 3 & 15 \\
\hline 3 a 4 anos & 4 & 20 \\
\hline 5 anos & 13 & 65 \\
\hline \multicolumn{3}{|l|}{ Principal função exercida na escola } \\
\hline Funções Docentes & 13 & 65 \\
\hline Funções de Chefia de Topo e Intermédia & 5 & 25 \\
\hline Funções de Formador & 2 & 10 \\
\hline
\end{tabular}

Fonte | Dados das entrevistas (elaboração própria) 
Do quadro ressalta um relativo equilíbrio entre o sexo masculino e feminino, bem como ao nível das faixas etárias dos respondentes, embora com maior peso de sujeitos entre os 31 e os 40 anos. Quanto às habilitações literárias, $50 \%$ dos informantes-chave possuíam o grau de licenciatura enquanto $45 \%$ possuíam o mestrado, e apenas 5\%, o grau de doutor. É de assinalar que $65 \%$ dos entrevistados, ou seja os docentes com 8 a 14 anos de serviço e os que se situam entre os 13 e 40 anos, que se constituíram como informantes-chave estavam, segundo Gonçalves (2009), num período das suas carreiras docentes de forte instabilidade, períodos críticos de questionamento, que podem conduzir a divergências positivas ou negativas, com naturais impactos em toda a sua prática docente. Relativamente à antiguidade, a maioria dos respondentes (65\%) encontravam-se há 5 anos na escola, sendo de frisar que este é o período máximo expectável, pois 5 anos era precisamente o número de anos de funcionamento da escola. Quanto à principal função exercida na organização escolar, apesar de ser recorrente a acumulação de múltiplas funções, a maioria dos respondentes dedicava-se eminentemente a funções docentes $(65 \%)$, enquanto $25 \%$ possuíam cargos de chefia e $10 \%$ funções de formador externo ou interno.

\section{Resultados}

Conforme exposto no capítulo introdutório, centrando-nos numa das dimensões que fizeram parte do guião de entrevista, a dimensão respeitante às "conceções e práticas sobre a concretização das políticas de formação contínua no contexto concreto da escola" que pretenderam, aquando da aplicação das entrevistas semiestruturadas, identificar referências que permitissem caracterizar as conceções sobre as políticas de formação contínua - especificamente sobre a formação centrada na escola - e recolher dados sobre as conceções e práticas sobre a concretização dessas políticas de formação contínua no projeto educativo e no desenvolvimento profissional docente, foi possível chegar ao Quadro 3 que clarifica o número de referências absolutas e relativas de cada uma das categorias da já citada dimensão. 


\section{Quadro 3}

Distribuição de Unidades de Registo das Categorias da Dimensão 4

\begin{tabular}{|c|c|c|c|}
\hline Dimensão & Categoria & fr. & $\%$ \\
\hline \multirow{8}{*}{$\begin{array}{l}\text { Conceções e } \\
\text { práticas sobre a } \\
\text { concretização das } \\
\text { políticas de for- } \\
\text { mação contínua } \\
\text { no contexto con- } \\
\text { creto da escola }\end{array}$} & Associação livre de ideias & 123 & $8,1 \%$ \\
\hline & Compreensão & 21 & $1,4 \%$ \\
\hline & Valoração & 13 & $0,9 \%$ \\
\hline & Aplicação das políticas de formação contínua & 262 & $17,3 \%$ \\
\hline & Projeto educativo & 154 & $10,2 \%$ \\
\hline & Formação contínua e projeto educativo & 139 & $9,2 \%$ \\
\hline & Formação contínua e desenvolvimento profissional docente & 229 & $15,1 \%$ \\
\hline & Total parcial & 941 & $62,2 \%$ \\
\hline
\end{tabular}

Fonte | Dados das entrevistas (elaboração própria)

Da análise é possível constatar que os respondentes colocaram grande enfoque na categoria 4, "Aplicação das Políticas de Formação Contínua" e na categoria 7, respeitante à "Formação Contínua e Desenvolvimento Profissional Docente", tendo-se optado por selecionar estas duas categorias para a análise que se apresenta ulteriormente. Dentro de cada categoria optou-se por destacar os indicadores em que se verificou um peso relativo superior a $10 \%$.

\section{Quadro 4}

Distribuição de Unidades de Registo da Categoria 4 da Dimensão 4 (N=262)

\begin{tabular}{|l|c|c|c|}
\hline \multicolumn{1}{|c|}{ Indicadores } & $\begin{array}{c}\text { Fonte } \\
\text { (Nentrevistados) }\end{array}$ & Fr. & $\%$ \\
\hline $\begin{array}{l}\text { Formas de Diagnóstico das Ações de Formação } \\
\text { promovidas pela Escola }\end{array}$ & 19 & 49 & $18,6 \%$ \\
\hline Diferenças em relação a outras formações & 15 & 34 & $12,9 \%$ \\
\hline Objetivos/Finalidades & 13 & 30 & $11,4 \%$ \\
\hline $\begin{array}{l}\text { Formas de Avaliação das Ações de Formação } \\
\text { promovidas pela Escola }\end{array}$ & 12 & 19 & $7,2 \%$ \\
\hline Critical Friends & 6 & 18 & $6,8 \%$ \\
\hline Reflexão Docente & 12 & 17 & $6,5 \%$ \\
\hline
\end{tabular}

Fonte | Dados das entrevistas (elaboração própria). 
No que diz respeito à categoria 4 relativa à "Aplicação das Políticas de Formação Contínua" foi valorizada a importância do diagnóstico das necessidades de formação, a clarificação dos objetivos das ações formativas a desenvolver bem como as especificidades das ações de formação centradas na escola, comparativamente às ações promovidas pelos Centros de Formação das Associações de Escola (CFAE). De igual forma, embora com menor expressão relativa, a importância de práticas reflexivas e dos critical friends na planificação e desenvolvimento das ações de formação.

No que concerne às "Formas de Diagnóstico das Ações de Formação promovidas pela Escola", um dos elementos com funções diretivas refere explicitamente que não existem organismos formais que tenham como função o diagnóstico de necessidades formativas. "[...] Não há nenhum organismo encarregado de detetar necessidades de formação" (E 14, 2015), indicando, à semelhança de outros entrevistados, que entre outros órgãos ou instâncias que cumprem essa função, encontram-se as direções de ciclo "cujos diretores têm de conhecer bem os professores que têm à frente para conseguirem proporcionar formações adequadas" (E 1, 2015), os próprios conselhos de turma "[...] uma saída muito importante de informação é o Conselho de Turma" (E3, 2015; E4,

52 2015), e a aplicação de determinados instrumentos de recolha de dados, como questionários "[...] são detetadas necessidades, são feitos estudos, são feitas observações, inquéritos, o que seja, diagnosticadas através dos alunos, com toda a subjetividade que esses questionários, às vezes, têm" (E4, 2015). A forma que terá um papel mais determinante é o diagnóstico a partir dos diferentes departamentos, "[...] eu diria que as necessidades são mais formalizadas ao nível dos departamentos" (E 14, 2015; E 10, 2015; E 1 1, 2015; E12, 2015; E17, 2015 ; E19, 2015) através dos seus respetivos coordenadores que "[... ] têm aqui um papel absolutamente fundamental de tentarem perceber junto dos seus pares as necessidades formativas, como primeiro elo de ligação à administração e à direção da escola" (E 13, 2015).

Dentro de cada departamento existe a possibilidade de auscultar as sensibilidades individuais de cada docente, por forma a identificar necessidades formativas "[...] uma avaliação daquilo que poderiam ser lacunas por resolver" (E2, 2015), daí se poder assumir, alguma abertura, pelo menos ao nível dos conteúdos, para a assunção de lógicas formativas down-top contrariando uma certa tendência referida na literatura para políticas formativas eminentemente assentes em lógicas top-down. "Em termos de conteúdo não será 
top-down, não sei, em termos de forma sim" (E2O, 20 15). Opinião contrária teve outro respondente, ao considerar que os interesses gerais da escola estarão a sobrepor-se aos interesses particulares dos docentes "[...] as ações de formação não foram propostas a partir de necessidades que os professores tenham verbalizado. As ações de formação foram propostas, porque a liderança pretende um caminho para este colégio ou por opções estratégicas" (E 15, 2015), talvez se percebendo pelo que foi transmitido pelo entrevistado seguinte, quando refere que "se nós vamos conseguindo perceber que há partes do nosso projeto educativo que ainda não vemos plasmadas nos nossos alunos, então, nós temos claramente de recuperar essas áreas" (E 15, 2015).

Quanto ao indicador "Diferenças em relação a outras formações", estas assentam muito na identidade da escola. "[...] É muito mais abrangente e, de alguma forma, para além de abrangente, tem que ver com [...] as nossas raízes identitárias, com as nossas bases, os nossos pilares" (E 10, 2015), no estabelecimento de uma comunidade de aprendizagem em que "somos membros da mesma comunidade. E pode haver, por exemplo, partilha de soluções para situações que todos vivemos" (E7, 2015), onde todos se conhecem e reconhecem. "[...] Nas outras ações de formação por onde eu passei, não conhecíamos os formadores, nem eles a nós [...] e aqui, no colégio, procuramos que sejam as próprias pessoas aqui de dentro a poder ir contribuindo para a formação" (E 14, 2015) e se vão apoiando cooperativamente "[...] aqui, há uma preocupação de envolvimento de todos os professores, de ter muito claro qual é o objetivo que se pretende e de se ter tido a capacidade de mobilizar os professores para esse trabalho de formação" (E8, 2015). Outros aspetos apontados foram o facto de no caso desta escola as ações de formação serem mais direcionadas em função dos objetivos da escola em concreto.

Eram ações mais fechadas [as ações externas]. Tinham um fim, quase à partida. Eram ações que geravam pouca reflexão e geravam muito pouco caminho. Aqui, é o contrário. Nós somos chamados a estar presentes, a participar e a pensar e a tomar decisões. No fundo, a fazer caminho e a crescer (E4, 2015).

Neste sentido, não se encontra adstrita, às diferentes ações de formação, a preocupação de obtenção de créditos que possibilite a progressão na carreira, como sucede muitas vezes no contexto do ensino público. "[...] É um bocadinho diferente do contexto da escola pública, onde, de facto, segundo 
aquilo [NOTA - a creditação da formação] se valoriza muito e, de facto, são aspetos importantes na progressão da carreira" (E5, 2015).

Relativamente aos "Objetivos/Finalidades" centrais da política de formação da escola apontam fortemente no sentido de capacitar os docentes para a materialização do projeto educativo da escola, "possibilitar a quem trabalha na escola um percurso fiel àquilo que fica definido num projeto educativo [...] fazer cumprir o projeto educativo, nas suas dimensões, mas muito na qualificação das práticas dos professores" (E5, 2015; E8, 2015; E 16, 2015), um fazer escola, sempre importante mas ainda mais quando estamos perante uma escola recém-criada, pelo que "[...] as ações de formação são implementadas sempre no sentido de, uma vez que nós temos uma escola com cinco anos, é aquilo que nós chamamos o fazer escola" (E9, 2015) onde se criam as bases fundacionais da mesma. "[...] Foi um objetivo muito fundacional, criar uma base onde possa assentar agora o crescimento da escola" (E 17, 2015). Paralelamente, para muitos dos respondentes, as ações de formação pretendem uma reflexão e questionamento constantes quanto à mudança de práticas que possam melhorar a qualidade do ensino prestado, com reflexos em contexto de sala de aula:

[...] dotando os professores de estratégias e metodologias úteis que possam gerar alguma mudança na nossa prática [...] procurando dar mais sentido àquilo que fazemos, de o fazermos melhor, de forma mais integrada (E2, 2015; E4, 2015; E9, 2015).

[...] um objetivo maior que era de alterar ou de orientar as práticas dos professores para práticas que permitissem uma maior aproximação às dificuldades dos alunos e, com isso, desenvolver processos de diferenciação na sala de aula, onde a avaliação formativa pudesse ter um impacto que não estava a ter (E8, 2015).

Apresenta-se de seguida o Quadro 5 que apresenta a contagem de frequências absolutas e relativas respeitantes à categoria 7 relativa à "Formação Contínua e Desenvolvimento Profissional Docente", da dimensão 4 em apreço. 


\section{Quadro 5}

Distribuição de Unidades de Registo da Categoria 7 da Dimensão 4 (N=229)

\begin{tabular}{|l|c|c|c|}
\hline \multicolumn{1}{|c|}{ Indicadores } & $\begin{array}{c}\text { Fonte } \\
\text { (N Entrevistados) }\end{array}$ & Fr. & $\%$ \\
\hline Constrangimentos & 19 & 37 & $16,2 \%$ \\
\hline Implicação (Ações marcantes) & 19 & 35 & $15,3 \%$ \\
\hline $\begin{array}{l}\text { Aplicação (Mudança de Práticas - Contexto } \\
\text { Departamentos) }\end{array}$ & 16 & 31 & $13,5 \%$ \\
\hline $\begin{array}{l}\text { Aplicação (Mudança de Práticas - Contexło } \\
\text { Sala Aula) }\end{array}$ & 17 & 22 & $9,6 \%$ \\
\hline Valoração Pessoal & 13 & 21 & $9,2 \%$ \\
\hline $\begin{array}{l}\text { Desenvolvimento Profissional - Competências } \\
\text { didáticas }\end{array}$ & 11 & 17 & $7,4 \%$ \\
\hline
\end{tabular}

Fonte | Dados das entrevistas (elaboração própria)

Podemos constatar que os indicadores que foram mais valorizados, tanto a nível de representatividade, 19 dos 20 entrevistados e no mesmo sentido ao nível do número de registos, foi o elencar de "Constrangimentos" e "Implicação (Ações marcantes)", seguido pelas referências a mudanças de práticas, particularmente ao nível dos departamentos, mas também em contexto de sala de aula. De relevar também que os entrevistados apontaram muito no sentido de, paralelamente a um desenvolvimento profissional docente, poder ter lugar uma valoração e desenvolvimento pessoais. De entre as diferentes competências docentes, os dados resultantes das entrevistas parecem apontar para um maior destaque no que concerne ao desenvolvimento de competências didáticas.

Quanto aos "Constrangimentos", o principal aspeto que emerge das entrevistas está alinhado com inúmeros estudos presentes na literatura que remetem para a questão da falta de tempo, "[...] o nosso principal constrangimento tem sido, efetivamente, o tempo [...] estares mentalmente disponível para uma formação que acontece normalmente depois das aulas" (E4, 2015; E5, 2015; E8, 2015; E10, 2015; E11, 2015; E13,2015; E17, 2015; E19, 2015; E20, 2015), notando-se uma grande preocupação também ao nível da planificação que aponta para alguma gestão menos correta, particularmente no que diz respeito aos períodos de implementação: 
Acabamos por condensar muito as formações nesta altura do ano $[\ldots]$ as coisas vão-se prolongando muito ao longo do tempo. Depois, quando nós retomamos, já perdemos um bocadinho o fio condutor [...] não fazemos um planeamento das ações de formação com a devida antecedência [...] a questão dos horários de formação é sempre um obstáculo (E2, 2015; E7, 2015; E15, 2015; E19, 2015).

Os resultados não deixam de evidenciar, igualmente, alguns constrangimentos ao nível da articulação entre diferentes ciclos, quando é expresso que "[... neste sistema de trabalho entre ciclos [...] o nosso ciclo tem sempre um calendário diferente dos outros. E há também lógicas próprias de ciclo que podem não facilitar" [E1, 2015; E16, 2015).

Quando questionados quanto à sua "Implicação (Ações marcantes)", a maioria dos respondentes apontou as formações que se focaram na designada pedagogia inaciana, pedagogia em que assenta e se desenvolve o projeto da escola. "Pedagogia inaciana, porque vão muito dentro de nós e isso é uma parte que eu gosto de explorar, o que se passa aqui dentro de mim [...] Não sabia o que era a pedagogia inaciana e, portanto, gostei de ficar a saber. E, 56 depois, porque me reconheci muito nela" (E1, 2015; E2, 2015; E7, 2015; E9, 2015; E10, 2015; E11, 2015; E17, 2015; E19, 20151, mas de igual forma um destaque para as ações de formação centradas nas necessidades educativas especiais "[...] particularmente as ações relativas às necessidades educativas especiais [...] uma por exemplo que se focou nas linguagens aumentativas" $(E 1,2015 ; E 15,2015)$, bem como uma oficina de formação plurianual que tem tido lugar na escola em que os docentes são levados a refletir no objeto de avaliação das suas disciplinas e de como devem os alunos ser avaliados. "[...] A formação 'avaliação das aprendizagens' [...] a formação em avaliação tem contribuído muito para o meu desenvolvimento enquanto profissional" (E3, 2015; E4, 2015; E5, 2015; E12, 2015).

Por fim, quanto à "Aplicação (Mudança de Práticas - Contexto Departamentos)" foi referido em primeiro lugar um reforço do conhecimento pessoal e profissional entre os membros de cada departamento, pois "[...] foi refletindo sobre a nossa prática avaliativa que nós acabámos por nos conhecer melhor enquanto professores e enquanto departamento. E mudámos uma série de práticas" (E 10, 2015), para além de uma partilha e reflexão dentro do contexto específico de cada departamento "[...] a que chamamos de partilha 
de boas práticas [...] grupos cooperativos em que estamos sempre a discutir sobre a prática, numa supervisão interpares muito importante" [E 1 1, 2015; E 16, 2015) que se alargou a uma dimensão inter-departamental, "[...] partiu-se para a construção de uma efetiva comunidade de aprendizagem" (E 1 1, 2015) que tem contribuído para o aprofundamento de práticas colaborativas e de assunção dos professores como co-responsáveis e construtores da sua própria formação contínua:

[...] um reforço da capacidade de trabalhar colaborativamente [...] entre colegas, começamos a falar já muito ou cada vez mais a mesma linguagem [...] há claramente um sentimento colegial e de comunidade no sentido de irmos analisar o que temos, vamos construir um projeto de formação e vamos verificar os resultados desse projeto (E5, 2015; E7, 2015; E8, 2015).

\section{Considerações finais}

Apesar do estudo apresentado ser de natureza qualitativa e suportar-se em resultados preliminares referentes a um estudo de caso, que inviabiliza assim qualquer pretensão generalizadora, não deixa de apontar algumas evidências que podem contribuir para uma maior reflexão destas temáticas.

Os resultados parecem apontar para a existência nesta escola de uma formação centrada na sua realidade, em linha com o defendido por ten Dam e Blom (2006), Nóvoa (2009), Hilton, Flores e Niklasson (2013) e Flores (2015), levando ao estabelecimento de uma comunidade de aprendizagem que reflete na e sobre a prática, procurando conduzir a um desenvolvimento profissional que possa ter reflexos nas aprendizagens dos alunos (FULLAN, 1991). Desta forma, as ações de formação promovidas na organização escolar encontram-se em linha com o projeto educativo embora se notem evidências que apontam para um certo desfasamento entre a políitica formativa e as quatro vertentes deste documento orientador.

No que diz respeito ao diagnóstico das necessidades de formação, os resultados parecem indicar que não existe um organismo formal responsável para essa função, diluindo-se por toda a estrutura organizacional, embora com particular destaque para o papel dos departamentos curriculares e dos 
professores em particular, aproximando-se estes aspetos ao que nos apontam Loucks-Horsley, Hewson, Love e Stiles (1998) e Gordon, Jacobs e Solis (2014).

Da interpretação dos dados é também possível retirar evidências que parecem apontar para um alinhamento com os paradigmas do deficit e do crescimento enunciados por Eraut ( 1977) enquanto sustentação para o lançamento das ações de formação.

estudo registou ainda evidências que vão ao encontro de Jesus (2000) e Rocha (20 1 4) quando apontam para as oportunidades adstritas à valorização intrínseca das ações de formação, sem a preocupação do formalismo da creditação. Neste caso particular, os principais objetivos que presidiram ao lançamento das ações de formação foram uma perspetiva fundacional de construção da escola e buscar a mudança de práticas com reflexos nas aprendizagens dos alunos, verificando-se uma assinalável implicação docente nas ações que se centraram no designado paradigma pedagógico inaciano, numa oficina de formação relativa à reflexão dos critérios de classificação das diferentes disciplinas e em ações que abordavam as questões das necessidades educativas especiais.

Apesar de ser consensual a ideia de uma profícua e efetiva construção de uma comunidade de aprendizagem docente (CLARKE; HOLLINGSWORTH, 2002), através do investimento em práticas reflexivas (WALLACE, 1991), é de relevar o tempo como principal constrangimento no âmbito da planificação e consequente implementação das ações de formação, dificuldade amplamente presente na literatura, como em Roy, Dufault e Châteauvert (20 14).

Adicionalmente, é de salientar que se observaram algumas evidências em sintonia com o exposto por Bell e Day (1991) que alertam para o facto de uma formação centrada na escola poder focar-se excessivamente no campo organizacional, olvidando a dimensão individual, o respeitante às necessidades e expectativas particulares de cada docente.

Com esta investigação pretende-se, como já exposto, contribuir para uma maior reflexão - tanto no contexto português, como brasileiro - do papel que a formação contínua, centrada na escola, poderá ter no desenvolvimento profissional dos professores. 


\section{Referências}

ASHBURN, Elizabeth. Teacher-led Inquiry: a compelling direction for the education of teachers. Action in Teacher Education, v. 17, n. 3, p. 79-86, 1995.

BARDIN, Laurence. Análise de conteúdo. Lisboa: Edições 70, 2009.

BARROSO, João. Formação, projecto e desenvolvimento organizacional. In: CANÁRIO, Rui (Org.). Formação e situações de trabalho. Porto: Porto Editora, 1997.

BELL, Les; DAY, Christopher. Managing professional development of teachers. Milton Keynes: Open University, 1991.

BOGDAN, Robert; BIKLEN, Sari. Investigação qualitativa em educação - uma introdução à teoria e aos métodos. Porto: Porto Editora, 1994.

BOLIVAR, Antonio. Liderazgo, mejora y centros educativos. In: MEDINA, Antonio Rivilla (Org.). El liderazgo en educación. Madrid: UNED, 1997.

CANÁRIO, Rui. Centros de Formação das Associações de Escolas: Que Futuro? In: AMIGUINHO, Abilio; CANÁRIO, Rui (Org.). Escolas e mudança: o papel dos centros de formação. Lisboa: Educa, 1994.

CANÁRIO, Rui. O estabelecimento de ensino no contexto local. Lisboa: Educa, 1992.

CONSELHO Científico-Pedagógico da Formação Contínua (CCPFC). Relatório de atividades do Conselho Científico-Pedagógico de Formação Contínua - Relatório de 2014. Braga: CCPFC, 2015. Disponível em: http://www.ccpfc.uminho.pt/Default.aspx?tabindex $=2 \&$ tabid=20\&pageid=50\&lang=pt-PT. Acesso em: 3 set. 2016 .

CLARKE, David; HOLLINGSWORTH, Hilary. Elaborating a model of teacher professional growth. Teaching and Teacher Education, n. 18, p. 947-967, nov. 2002.

CORNISH, Linley; JENKINS, Kathy Ann. Encouraging teacher development throught embedding reflective practice in assessment. Asia-Pacific Journal of Teacher Education, v. 40, n. 2, p. 159-170, 2012.

DAY, Christopher. Desenvolvimento profissional de professores: os desafios da aprendizagem permanente. Porto: Porto Editora, 2001.

DUBAR, Claude. Formação, trabalho e identidades profissionais. In: CANÁRIO, Rui (Org.). Formação e situações de trabalho. Porto: Porto Editora, 2003. 
E1. Entrevista. Lisboa (Lisboa), 22 jul. 2015.

E2. Entrevista. Lisboa (Lisboa), 8 jul. 2015.

E3. Entrevista. Lisboa (Lisboa), 24 jul. 2015.

E4. Entrevista. Lisboa (Lisboa), 20 jul. 2015.

E5. Entrevista. Lisboa (Lisboa), 24 jul. 2015.

E7. Entrevista. Lisboa (Lisboa), 29 jun. 2015.

E8. Entrevista. Lisboa (Lisboa), 27 jul. 2015.

E9. Entrevista. Lisboa (Lisboa), 23 jun. 2015.

E 10. Entrevista. Lisboa (Lisboa), 8 jul. 2015.

E 11 . Entrevista. Lisboa (Lisboa), 10 jul. 2015.

E12. Entrevista. Lisboa (Lisboa), 3 jul. 2015.

E 13. Entrevista. Lisboa (Lisboa), 6 jul. 2015.

60 E14. Entrevista. Lisboa (Lisboa), 27 jul. 2015.

E 15. Entrevista. Lisboa (Lisboa), 3 jul. 2015.

E 16. Entrevista. Lisboa (Lisboa), 30 jul. 2015.

E17. Entrevista. Lisboa (Lisboa), 29 jun. 2015.

E19. Entrevista. Lisboa (Lisboa), 9 jul. 2015.

E20. Entrevista. Lisboa (Lisboa), 18 jun. 2015.

ERAUT, Michael. Some perspectives on consultancy in in-service education. In-service Education Journal, v. 4, n. 1/2, p. 95-99, 1977.

FLORES. Maria Assunção. Formação de professores: questões críticas e desafios a considerar. In: COMISSÃO Nacional de Educação. Estado da Educação 2014. Lisboa: Comissão Nacional de Educação, 2015.

FORTE, Ana Maria; FLORES, Maria Assunção. Teacher collaboration and professional development in the workplace: a study of Portuguese teachers. European Journal of Teacher Education, v. 37, n. 1, p. 91-105, 2014. 
FULLAN, Michael. The new meaning of educational change. Chicago: Teacher College Press, 1991.

FURLONG, John. Ideology and reform in teacher education in England. Some reflections on Cochran-Smith and Fries. Educational Researcher, n. 31 , n. 6, p. 23-25, aug./sep. 2002.

GONCCALVES, José Alberto. Desenvolvimento profissional e carreira docente - Fases da carreira, currículo e supervisão. Sísifo, n. 8, p. 23-36, jan./abr. 2009.

GORDON, Stephen; JACOBS, Jennifer; SOLIS, Rachel. Top 10 Learning needs for teacher leaders. Learning Forward, v. 35, n. 6, p. 48-52, 2014.

HARGREAVES, Andy. The emotional practice of teaching. Teaching and Teacher Education, v. 14, n. 8, p. 835-854, nov. 1998.

HARGREAVES, Andy; FULLAN, Michael. Introduction. Understanding Teacher Development. New York: Teachers College Press, 1992.

HARRIS, Deborah Lee; ANTHONY, Helene. Collegiality and its role in teacher development: perspectives from veteran and novice teachers. Teacher Development, v. 5, n. 3, p. 371390, 2001.

HEllBRONN, Ruth. School based Teacher Training. Can it work? Mentoring \& Tutoring: Partnership in Learning, v. 3, n. 1, p. 62-65, 1995.

HERDEIRO, Rosalinda; SILVA, Ana Maria. Práticas Reflexivas: uma estratégia de desenvolvimento profissional dos docentes. In: COLÓQUIO LUSO-BRASILEIRO, 4; 2008, Florianópolis. Atas... Florianópolis: Universidade de Santa Catarina, 2008.

HILTON, Gillian; FLORES, Maria Assunção; NIKLASSON, Laila. Teacher quality, professionalism and professional development: findings from a European project. Teacher Development, v. 17, n. 4, p. $431-447,2013$.

HOOVER, Kristin. Reflections on student affect in group projects: are we encouraging our students to be in community with others? Jesuit Higher Education, v. 4, n. 1, p. 63-71, jan. 2015.

IMBERNÓN, Francisco. Formação docente e profissional: formar-se para a mudança e a incerteza. São Paulo: Cortez, 2006.

JESUS, Saúl Neves. Motivação e formação de professores. Coimbra: Quarteto Editora, 2000. 
KWAKMAN, Kitty. Factors affecting teachers' participation in professional learning activities. Teaching and Teacher Education, n. 19, p. 149-170, 2003.

LESNE, Marcel. Trabalho pedagógico e formação de adultos: elementos de análise. Lisboa: Fundação Calouste Gulbenkian, 1984.

LEVINE, Thomas; MARCUS, Alan. How the Structure and Focus of Teachers' Collaborative Activities Facilitate and Constrain Teacher Learning. Teaching and Teacher Education, v. 26, n. 3, p. 389-398, 2010.

LIMA, Jorge Ávila. As culturas colaborativas nas escolas: estruturas, processos e conteúdos. Porto: Porto Editora, 2002.

LITTLE, Judith Warren. The persistence of privacy: autonomy and initiative in teachers' professional relations. Teachers College Record, n. 91, p. 509-536, 1990.

LITTLE, Judith Warren. Norms of collegiality and experimentation: workplace conditions of school success. American Educational Research Journal, v. 19, n. 3, p. 325-340, 1982.

LOUCKS-HORSLEY, Susan; HEWSON, Peter; LOVE, Nancy; STILES, Katherine. Designing professional development for teachers of science and mathematics. Thousand Oaks, CA:

Corwin Press, 1998.

McLAUGHLIN, Terence. Teaching as a practice and a community of practice: The limits of commonality and the demands of diversity. Journal of Philosophy of Education, v. 37, n. 2, p. 339-352, 2003.

MUCHARREIRA, Pedro Ribeiro. O papel da formação contínua na (re)construção do projeto educativo e no desenvolvimento profissional docente. In: FÓRUM DE JOVENS INVESTIGADORES, 5; 2014 , Lisboa. Anais... Lisboa: Instituto de Educação da Universidade de Lisboa, 2014. Disponível em: http://www.ie.ulisboa.pt/pls/portal/docs/1/459831. PDF. Acesso em: 2 set. 2016.

NÓvOA, António. Para uma formação de professores construída dentro da profissão Lisboa: Educa, 2009.

Formação de professores e profissão docente. Lisboa: Instituto de Inovação Educacional, 1992.

ROCHA, Ana Paula. Formação contínua - na senda da alquimia da escola. Almadaforma, n. 4 , p. 38-40, fev. 2014.

ROGERS, Carl. Grupos de Encuentro. Buenos Aires: Amorrortu, 1973. 
ROLDÃO, Maria do Céu. Formação de professores baseada na investigação e na prática reflexiva. In: Conferência Desenvolvimento Profissional de Professores para a Qualidade e para a Equidade da Aprendizagem ao Longo da Vida; 2007, Lisboa. Anais... Lisboa: Presidência Portuguesa do Conselho da União Europeia, 2007.

ROSENHOLTZ, Susan. Teachers' workplace. New York: Longman, 1989.

ROY, Valérie; DUFAULT, Sacha Genest; CHÂTEAUVERT, Joanie. Professional co-development groups: addressing the teacher training needs of social work teachers. Journal of Teaching in Social Work, v. 34, n. 1, p. 29-45, 2014.

SCHÖN, Donald. Educando o profissional reflexivo. Porto Alegre: Artes Médicas Sul, 2000.

SILVA, Virgílio Rego. Escola autonomia e formação. Dinâmicas de poder e lógicas de acção numa escola secundária de braga. 221f. 2003. Dissertação (Mestrado em Educação) Instituto de Educação e Psicologia da Universidade do Minho, Braga, 2003.

STREETMAN, Heidi. Jesuit values, ignatian pedagogy and service learning: catalysts for transcendence and transformation via action research. Jesuit Higher Education, v. 4, n. 1, p. 36-50, 2015.

Ten DAM, Geert; BLOM, Sarah. Learning through participation. The potential of school-based teacher education for developing a professional identity. Teaching and Teacher Education, n. 22, p. 647-660, 2006.

TRINDADE, José Pedro; BAHIA, Sara; MUCHARREIRA, Pedro Ribeiro. Uma visão interdisciplinar integrada da Taxonomia de Bloom. In: COLÓQUIO DA AFIRSE - DIVERSIDADE E COMPLEXIDADE DA AVALIAÇÃO EM EDUCAÇÃO E FORMAÇÃO - CONTRIBUTOS DA INVESTIGAÇÃO, 22; 2015, Lisboa. Atas... Lisboa: EDUCA/AFIRSE Portugal, 2015.

VEIGA SIMÃO, Ana Margarida; CAETANO, Ana Paula; FLORES, Maria Assunção. Contextos e processos de mudança dos professores: uma proposta de modelo. Educação \& Sociedade, Campinas, v. 26, n. 90, p. 173-190, 2005.

WALLACE, Michael. Training foreign language teachers. A reflective approach. Cambridge: CUP, 1991. 
Artigo

Formação contínua centrada na escola e desenvolvimento profissional docente: um estudo de caso

Prof. Assistente Pedro Ribeiro Mucharreira

Universidade de Lisboa Instituto de Educação Membro da UIDEF - Unidade de Investigação e Desenvolvimento em Educação e Formação E-mail | pedro.mucharreira@campus.ul.pt

Recebido 13 set. 2016 Aceito 27 out. 2016 